\title{
POPULATION'S SOCIAL SENTIMENT, Q2 2016
}

\author{
E. Avraamova, D. Loginov
}

Research findings obtained by the Institute of Social Analysis and Forecasting, RANEPA, demonstrate that in Q2 2016 the population with more optimism began looking to the future, which testifies about the adaptability potential of the respondents. The research provides negative stabilization with the emphasis on greater adaptability. Except the middle class, it to a considerable extent, is observed in the archaic forms of employment (for instance, private plots) ${ }^{2}$.

\section{Dynamics of the estimate change}

In May 2016, assessing the scale of the crisis, the population opted in favor of stabilization of the situation: the largest group comprising $35 \%$ against $24 \%$ in February 2016 regard the situation on hold. The number of respondents who observe significant deterioration has dropped. Thus, a relative moderation has taken place regarding what is happening in the economy.

The prospects of economic recovery get more optimistic assessments. The number of those who previously thought that it would take a protracted character. Simultaneously, the number of citizens whose material well-

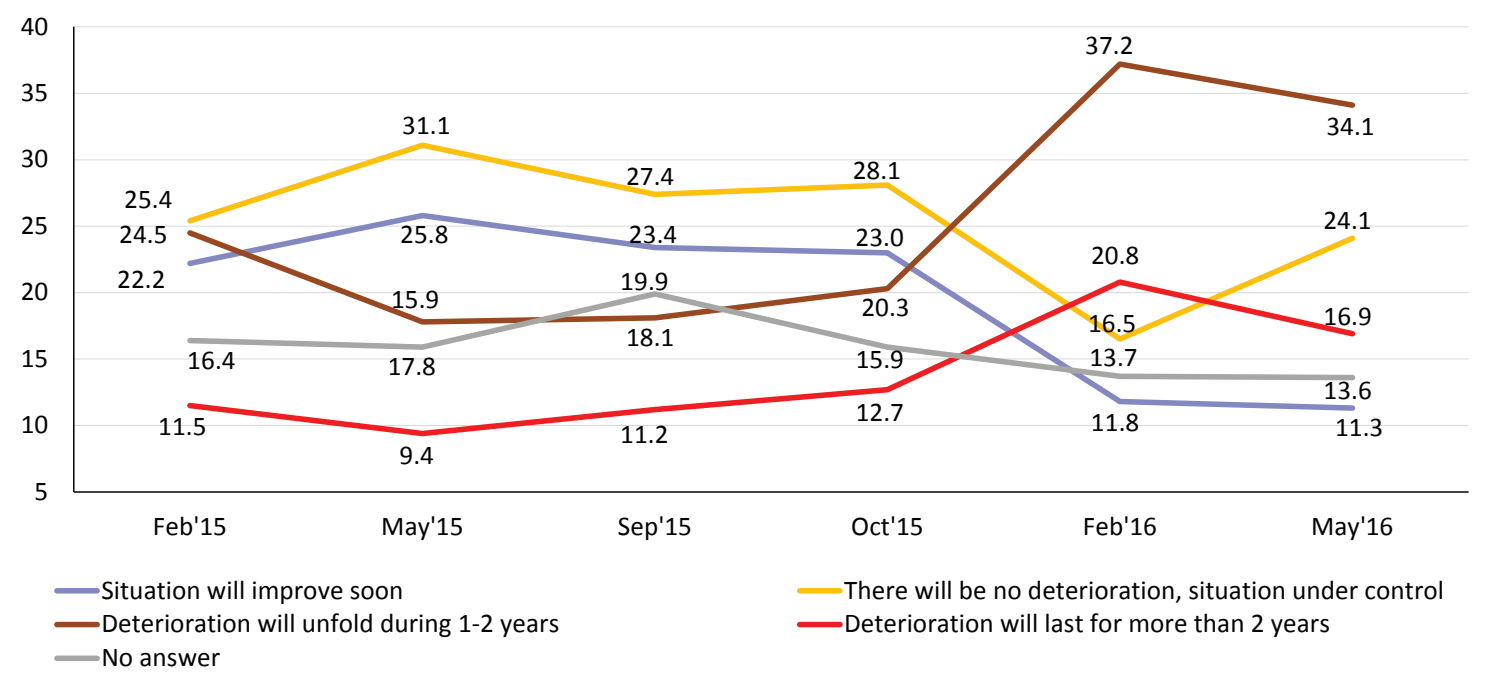

Fig. 1. Assessment of duration of negative effects in the economy, \%

1 This paper was originally published in Online Monitoring of Russia's Economic Outlook No.11(29).

2 The population's social sentiment is represented through dynamics of the population's assessments of the current economic outlook, prospect for economic recovery as well as situation in the spheres of employment and consumption and assessments of risks of standard of living reduction. Adaptability strategy of the population was studied aimed at reflecting corresponding risks. The state of Russian middle class in the current situation was investigated. Monitoring "Social Assessment of Crisis" (along representative sample 1,600 respondents are interviewed monthly) and special study "Inequality Challenges) (in April 2016, 3,600 respondents across Russia were interviewed) conducted by the Institute served as an information basis for the research. 
being deteriorated during the crisis has shrunk by $5 \%$. Furthermore, the number of those whose situation improved has not grown.

General more positive assessments of the current economic outlook as before do not correlate with the assessment of employment situation. The same share of respondents as in previous surveys (15\%) respond about the job loss ${ }^{1}$. Simultaneously, negative expectations regarding the possibility to

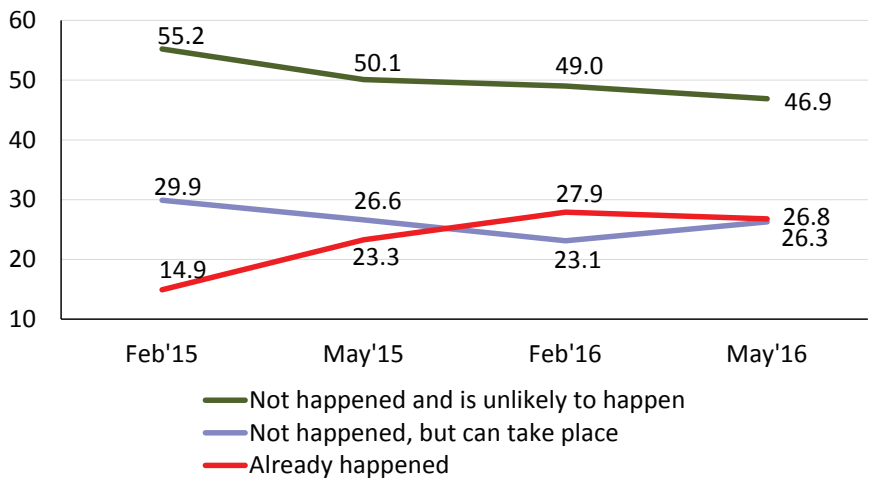

Fig. 2. Wage reduction, $\%$ lose a job are growing. Precisely the same trends are observed regarding dynamics of wage size: the same number of respondent inform about its reduction as before and negative expectations have grown somewhat.

Eight percent of respondent register transition to subemployment, $11 \%$ to informal employment, and it broadly matches with the previous survey. The indicator regarding back pay is still high $-20 \%$ of interviewed register it.

Wi the first surveys, we observed a reduction of consumer activity among the population. However, compared to the previous months there is no further contraction of spending on goods and services. Negative expectations regarding the need to reduce consumer spending in the future do not grow either.

\section{The status of the middle class}

It is important to study the status of the middle class because hopes are rested in it for resolving the current situation, which not always and not by everybody is qualified as a crisis but undoubtedly is considered complicated.

The Russian middle class is extremely inhomogeneous. Its representatives come across all economic activities. This social stratum is most obviously observed in public administration, law enforcement, and financial activity. The share of employed in potentially innovation sectors (high-tech, education, health care, and science) is contracting in the middle class.

Those whose material status has not deteriorated during the crisis prevail among the middle class. Possible, it is due to the fact that in virtue of their competitive advantages the middle class representatives work at enterprises whose economic situation is better compared to other enterprises.

Lower stratum of society face notably higher risks of job loss than representatives of the middle class. In the perception of the majority of surveyed independently of the stratification group quest for a new job currently is connected with big difficulties. Moreover, according to $30 \%$ of representatives of lower stratum of society, it is practically impossible to find a new job. Around $20 \%$ of the middle class representatives think the same. This testifies to a contraction of the labor market and weak labor mobility.

Middle class to a greater extent than lower stratum of society manage to maintain the consumption level, however it is subject to costs saving: the share of those who cut consumption exceeds half of the middle class number.

$1 \quad$ With possible further employment. 
There are significantly fewer those who save on food, clothes and footwear, and especially on medicine, but they had to decline certain paid services, entertainment, and trips.

The resources of the middle class exceed the resources of lower stratum: its representatives oftener have relatively large savings (which permit to live for half year or longer), owners of second housing, and oftener have additional employment. The middle class representatives also have a more significant amount of property. The majority (62\%) of the middle class have a complete set, which is quite modern. However, lower stratum lags behind not by much in this respect $-46 \%$ of the corresponding stratum have good material provision. In this extent, 'fat' years with high consumption were not for nothing.

At the same time, there is a significant group of middle class which needs to renovate possessions. Less than a third of this group have financial possibility for renovation. Consequently, reduction of the consumption activity can be viewed as a rather compressed in time adaptability strategy.

\section{Adaptability behavior}

In the curse of recent six months just half of the population (49.2\%) took any actions aimed at saving of spending their funds. On the assumption of actions (or inactions) of Russians during last year, we managed to reveal several adaptability strategies of the population to the dynamic life environment.

The investment strategy is the rarest $(4.8 \%)$. It envisages the purchase of the investment assets and accumulation of funds. The savings strategy is a little bit more popular (13.6\%). Its followers accumulate funds without purchasing the investment products nor durable goods. Change of profession (16.3\%) through obtaining corresponding education is another strategy aimed at saving funds. The consumption strategy $(33.3 \%)$ is mainly aimed at purchase of durable goods. Strategy of survival $(32.0 \%)$ is the last one. It is characterized by the fact that its followers commenced using their plots of land more actively. Thus, traditional (archaic strategy) has the best of all the other.

The middle class stands out from the general structure of the population as a carrier of adaptability strategies: only $35 \%$ of its members lack adaptability strategies against $61.5 \%$ in the lower stratum.

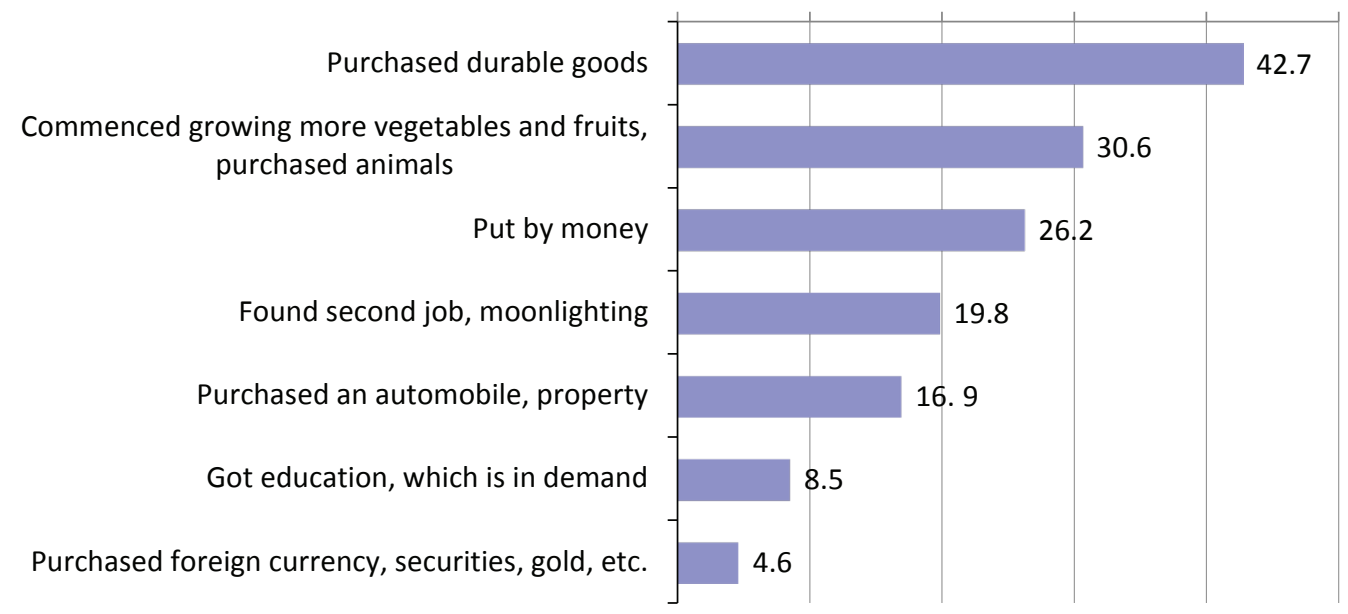

Fig. 3. Actions of Russians during the last half year, in $\%$ of those who did not take actions (several responses were accepted) 
Around one fifth of the middle class has invested in means of transport and property and is active adherents of the savings strategy. Give a cushion in the form of durables also largely corresponds the middle class behavior. The use of private plots of land as a survival is not its strategy. 